\title{
Supplementary Appendix A and B:
}

\author{
Erik Lindqvist \\ Research Institute of Industrial Economics (IFN)
}

September 23, 2008

\begin{abstract}
These Supplementary Appendices presents additional theoretical (A) and empirical (B) results for the paper "Privatization of Credence Goods: Theory and an Application to Residential Youth Care".
\end{abstract}

\section{Maximizing (2.1).}

From (2.1), we get

$$
V_{1}=p-\gamma[c q+F(e)]-C(e)+[1-\lambda(q)] V_{2}
$$

In case of private ownership, the owner's maximand is

$$
p-c q-F(e)-C(e)+[1-\lambda(q)] V_{2}
$$

FOC w.r.t. $e$ is:t

$$
-F^{\prime}(e)=C^{\prime}(e) .
$$

The uniqueness of this solution follows from the fact that $F(e)$ and $C(e)$ are both strictly convex. FOC w.r.t. $q$ is

$$
\begin{aligned}
-\lambda^{\prime}(q) V_{2} & =c \\
\alpha(1+q)^{-(1+\alpha)} V_{2} & =c,
\end{aligned}
$$

which can be reformulated as

$$
\begin{aligned}
\alpha(1+q)^{-(1+\alpha)} V_{2} & =c \\
q & =\left(\frac{\alpha}{c} V_{2}\right)^{\frac{1}{1+\alpha}}-1
\end{aligned}
$$

Hence, we have a function $q\left(V_{2}\right)$ where

$$
q\left(V_{2}\right)=\left(\frac{\alpha}{c} V_{2}\right)^{\frac{1}{1+\alpha}}-1
$$

if $\left(\frac{\alpha}{c} V_{2}\right)^{\frac{1}{1+\alpha}}>1$ and $q\left(V_{2}\right)=0$ otherwise.

We get the first derivative of $q\left(V_{2}\right)$ w.r.t. $V_{2}$ (assuming that $V_{2}$ is such that $q>0$ )

$$
\frac{\alpha}{(1+\alpha) c}\left(\frac{\alpha}{c} V_{2}\right)^{-\frac{\alpha}{1+\alpha}}>0
$$


and the second derivative

$$
-\frac{\alpha^{3}}{(1+\alpha)^{2} c^{2}}\left(\frac{\alpha}{c} V_{2}\right)^{-\frac{1+2 \alpha}{1+\alpha}}<0
$$

implying that there is a unique solution of $q$ for all $V_{2}$.

In case of public ownership, the manager's maximand is

$$
p-C(e)+[1-\lambda(q)] V_{2} .
$$

It follows that the manager sets $e=\underline{e}$ regardless of $V_{2}$. The manager is indifferent as to the level of quality in case $V_{2}=0$. If $V_{2}>0$, the manager uses all available resources on quality.

\section{Full solution: Private firm}

\section{The owner's problem}

As $-F^{\prime}(e)>C^{\prime}(e)$ for some $e>\underline{e}$, the owner always sets $e=e^{*}>\underline{e}$ where $e^{*}$ is such that $-F^{\prime}\left(e^{*}\right)=C^{\prime}\left(e^{*}\right)$. As $F^{\prime \prime}(e)>0$ and $C^{\prime \prime}(e)>0$ this solution is unique. The full solution to the owner's maximization problem is

$$
\{q, e\}= \begin{cases}q=0 \text { and } e=e^{*} & \text { if } p \leq \frac{c}{\alpha}+F\left(e^{*}\right)+C\left(e^{*}\right) \\ q=\frac{\alpha}{(1+\alpha) c}\left[p-F\left(e^{*}\right)-C^{\prime}\left(e^{*}\right)-\frac{c}{\alpha}\right] \text { and } e=e^{*} & \text { if } p>\frac{c}{\alpha}+F\left(e^{*}\right)+C\left(e^{*}\right) .\end{cases}
$$

The second order condition w.r.t. $q$ is

$$
\alpha(\alpha-1)[p-F(e)-C(e)] q^{\alpha-2}-2 \alpha c q^{\alpha-1}<0 .
$$

In the interior solution where $q \geq 0$, we have $q$ as a continuous function of $p$ with derivatives

$$
\begin{aligned}
\frac{\partial q}{\partial p} & =\frac{\alpha}{(1+\alpha) c} \\
\frac{\partial^{2} q}{\partial p^{2}} & =0 .
\end{aligned}
$$

To see that $V^{o}$ is continuously increasing in $p$, consider to prices, $p^{\prime \prime}$ and $p^{\prime}$ where $p^{\prime \prime}>p^{\prime}$. We have that

$$
V^{o}\left(p^{\prime \prime}\right) \geq \frac{p^{\prime \prime}-F\left(e^{*}\right)-C\left(e^{*}\right)+c q\left(p^{\prime}\right)}{\lambda\left(q\left(p^{\prime}\right)\right)}>\frac{p^{\prime}-F\left(e^{*}\right)-C\left(e^{*}\right)}{\lambda\left(q\left(p^{\prime}\right)\right)}=V^{o}\left(p^{\prime}\right) .
$$

As the owner's best outside option is equal to zero, there is a unique price, $\underline{p}=F\left(e^{*}\right)+C\left(e^{*}\right)$, such that the participation constraint binds, i.e., $V^{o}(\underline{p})=0$.

Total cost $\left(T^{o}\right)$ under private production is given by

$$
T^{o}(q)=p(q)= \begin{cases}F\left(e^{*}\right)+C\left(e^{*}\right) & \text { if } q=0 \\ \left(\frac{(1+\alpha) c}{\alpha}\right) q+F\left(e^{*}\right)+C\left(e^{*}\right)+\frac{c}{\alpha} & \text { if } q>0\end{cases}
$$

Note that the marginal cost of quality continuously approaches infinity as $\alpha$ approaches zero.

\section{The public agency's problem}

Let $\underline{p}=F\left(e^{*}\right)+C\left(e^{*}\right)$. The public agency's problem is then

$$
\begin{array}{ll}
\max _{p} & V^{p a}(B, p) \\
\text { s.t. } & p \geq \underline{p}
\end{array}
$$


where

$$
\begin{aligned}
V^{p a}(B, p) & =(B-p)(1+q(p))^{\alpha} \\
& =(B-p)\left(1+\frac{\alpha}{(1+\alpha) c}\left[p-F\left(e^{*}\right)-C\left(e^{*}\right)-\frac{c}{\alpha}\right]\right)^{\alpha} .
\end{aligned}
$$

The first derivative of $V^{p a}(B, p)$ with respect to $p$ is

$$
\begin{aligned}
& -\left(1+\frac{\alpha}{(1+\alpha) c}\left[p-F\left(e^{*}\right)-C\left(e^{*}\right)-\frac{c}{\alpha}\right]\right)^{\alpha} \\
& +\frac{\alpha^{2}}{(1+\alpha) c}(B-p)\left(1+\frac{\alpha}{(1+\alpha) c}\left[p-F\left(e^{*}\right)-C\left(e^{*}\right)-\frac{c}{\alpha}\right]\right)^{\alpha-1}
\end{aligned}
$$

In the interior solution, we thus get

$$
p^{*}=\frac{B \alpha+F\left(e^{*}\right)+C\left(e^{*}\right)-c}{1+\alpha}
$$

which is strictly increasing in $B$. The second derivative to the public agency's problem is

$$
-(1+\alpha)(1+q(p))^{\alpha-1} \frac{\partial q(p)}{\partial p}-\alpha(B-p)(1-\alpha)(1+q(p))^{\alpha-2} \frac{\partial q(p)}{\partial p}<0
$$

implying that the interior solution is unique. The condition for the existence of an interior solution is that the first derivative of $V^{p a}$ with respect to $p$ is positive for some $p>\frac{c}{\alpha}+F\left(e^{*}\right)+C\left(e^{*}\right)$. Substituting this expression into the first derivative above, we get

$$
B>\frac{(1+2 \alpha) c}{\alpha^{2}}+F\left(e^{*}\right)+C\left(e^{*}\right)=\widetilde{B}^{o} .
$$

Substituting $p^{*}(B)$ into $q(p)$, we get

$$
q\left(p^{*}(B)\right)=\frac{\alpha^{2}}{(1+\alpha)^{2} c}\left[B-F\left(e^{*}\right)-C\left(e^{*}\right)\right]-\frac{1+2 \alpha}{(1+\alpha)^{2}}
$$

which is strictly increasing in $B$.

Lemma A1 shows that there exists a unique value $B^{o}$ such that $V^{p a}\left(p^{*}(B)\right)>V^{p a}(\underline{p})$ for all $B>B^{o}$ and $V^{p a}\left(p^{*}(B)\right)<V^{p a}(p)$ for all for all $B<B^{o}$. In other words, the public agency will set a price that provides the owner with a rent from treatment in case quality is sufficiently important.

\section{Full solution: Public firm}

\section{The manager's problem}

The solution to the manager's problem is

$$
(q, e)= \begin{cases}q=\widetilde{q} ; e=\underline{e} & \text { if } p=C(\underline{e}) ; \\ q=q^{\max } ; e=\underline{e} & \text { if } p>C(\underline{e})\end{cases}
$$

Where $\widetilde{q}$ denotes the level of quality asked for by the public agency, and $q^{\text {max }}$ the maximum level of quality feasible given the resources available. Total cost under public provision $\left(T^{m}\right)$ is given by $F(e)+c q+p$, implying that we get

$$
T^{m}(q)=F(\underline{e})+C(\underline{e})+c q .
$$




\section{The public agency's problem}

First note that there is no point for the public agency to set $p>C(\underline{e})$ since $e$ is unaffected and the choice set of quality investments is the same. Since $e^{m}=\underline{e}$ and the public agency pays for all costs, we have that

$$
\max _{\{q\}} \quad[B-F(\underline{e})-C(\underline{e})-c q](1+q)^{\alpha}
$$

which gives FOC w.r.t. $q$ :

$$
\begin{aligned}
-c(1+q)^{\alpha}+\alpha[B-F(\underline{e})-C(\underline{e})-c q](1+q)^{\alpha-1} & =0 \\
\frac{\alpha}{c(1+\alpha)}\left[B-F(\underline{e})-C(\underline{e})-\frac{c}{\alpha}\right] & =q
\end{aligned}
$$

and the second order condition

$$
-c(1+\alpha)(1+q)^{\alpha-1}+(\alpha-1) \alpha[B-F(\underline{e})-C(\underline{e})-c q](1+q)^{\alpha-2}<0
$$

implying that the solution is unique.

\section{Microfoundation for assumption on ownership}

This section provides a simple formal argument for the assumption that firm owners pay the costs of production.

Consider an augmented model where production of the service requires the use of an asset $A$ which has market value $V_{t}$ at the onset of each treatment period. Under in-house production, $A$ is owned by the public agency. In case of service contracting, $A$ is owned by the private firm. Production leads to a depreciation of the value of $A$, but the agent can offset this by investing in the future value of $A$. Let $i$ denote an investment at cost $k(i)$ where $k(i)$ is increasing and strictly convex in $i$ with $k^{\prime}(0)>1$. For example, in the case of garbage collection, $k(i)$ could reflect resources spent on the maintenance of the trucks used to collect the garbage. The function $V_{t+1}(i)=V_{t}+i-\delta$ denotes the value of the asset at the end of treatment period $t$, where $\delta$ is the per-period depreciation of the asset value. I also assume that the optimal investment (i.e., $i^{*}$ such that $k^{\prime}\left(i^{*}\right)=1$ ) is equal to the level of depreciation $\delta$. This assumption simplifies the exposition but is not important for the results. When $i$ falls short of $i^{*}$, the agent invests too little as the marginal cost of increasing investments, $k^{\prime}(i)$, is below the marginal value, i.e., 1 . When $i$ is above $i^{*}$, the agent overinvests as it would now be socially optimal to reduce investments.

As before, the cost of producing a service of quality $q$ is $c q+F(e)$. Let $a$ denote the total expenditures of producing the service. The expenditures consists both of the direct cost and the investments, i.e.,

$$
a=c q+F(e)+k(i) .
$$

The key assumption here is that while $a$ is directly observable, the investment $k(i)$ cannot be separarated from the direct costs. For example, it is hard to disentangle the costs of regular equipment maintenance from investments that raise the long-term value of the equipment. As another example, it is hard to assess to what extent workforce training is a long-term investment. A third example is the implementation of administrative systems that increase the long-run effectiveness of the firm. However, in order to avoid extreme solutions, I assume that $i$ is bounded from below by zero, and from above by $\bar{i}>i^{*}$. Apart from ownership $(\gamma)$, a contract in the case of contracting on expenditures specifies a treatment fee $(p)$ and a share of expenditures $v \in\{0,1\}$. The public agency thus decides between a cost-plus contract $(v=0)$ and a fixed-price contract $(v=1)$.

In case of no contracting on costs or quality, the agent's maximization problem is

$$
\begin{array}{ll}
\max _{\{q, e, i\}} & \frac{p-C(e)-v[F(e)+c q+k(i)]+\gamma(i-\delta)}{\lambda(q)} \\
\text { s.t. } & i \in[0, \bar{i}] .
\end{array}
$$

The only exogenously imposed difference between private and public ownership is that $\gamma=1$ under private ownership whereas $\gamma=0$ under public ownership. 


\subsection{Public firm}

The manager of the public firm maximizes (1) where $\gamma=0$. There are two cases depending on the value of $v$. If $v=1$, the manager's problem is

$$
\begin{array}{ll}
\max _{\{q, e, i\}} & {[p-C(e)-(F(e)+c q+k(i))](1+q)^{\alpha}} \\
\text { s.t. } & i \in[0, \bar{i}] .
\end{array}
$$

implying that we get $e=e^{*}$ where $e^{*}$ is such that $-F^{\prime}\left(e^{*}\right)=C^{\prime}\left(e^{*}\right) ; i=0$, and

$$
q=\frac{\alpha}{(1+\alpha) c}\left[p-C\left(e^{*}\right)-F\left(e^{*}\right)-\frac{c}{\alpha}\right]
$$

if $p>C\left(e^{*}\right)+F\left(e^{*}\right)+\frac{c}{\alpha}$ and $q=0$ otherwise. Reformulating this expression gives the treatment fee as a function of quality for $q>0$

$$
p(q)=\frac{(1+\alpha)}{\alpha} c q+C\left(e^{*}\right)+F\left(e^{*}\right)+\frac{c}{\alpha}
$$

and

$$
p(q=0)=C\left(e^{*}\right)+F\left(e^{*}\right) .
$$

Since the public agency owns the asset, total cost for $q>0$ is given by

$$
T(q, v=1)=\left(\frac{1+\alpha}{\alpha}\right) c q+\frac{c}{\alpha}+C\left(e^{*}\right)+F\left(e^{*}\right)+\delta
$$

and

$$
T(q=0, v=1)=C\left(e^{*}\right)+F\left(e^{*}\right)+\delta
$$

for $q=0$.

If $v=0$, the manager's problem is

$$
\begin{array}{ll}
\max _{\{q, e, i\}} & {[p-C(e)](1+q)^{\alpha}} \\
\text { s.t. } & i \in[0, \bar{i}] .
\end{array}
$$

implying that we get

$$
e=\arg \min C(e)=\underline{e} .
$$

The manager is indifferent regarding the values of $i$ and $q$. Total cost is therefore

$$
T(q, v=0)=c q+C(\underline{e})+F(\underline{e})+k\left(i^{*}\right)
$$

where $i^{*}=\delta$ is such that $k^{\prime}\left(i^{*}\right)=1$. Since marginal cost of quality is strictly higher when $v=1$, it follows that $v=0$ is superior regardless of the preference for quality if total cost is lower under $v=0$ for zero quality. Hence, $v=0$ is always superior under public ownership in case

$$
\begin{aligned}
C\left(e^{*}\right)+F\left(e^{*}\right)+\delta & >C(\underline{e})+F(\underline{e})+k\left(i^{*}\right) \\
\delta-k\left(i^{*}\right) & >[C(\underline{e})+F(\underline{e})]-\left[C\left(e^{*}\right)+F\left(e^{*}\right)\right],
\end{aligned}
$$

That is, it is better for the public agency to pay the costs of production in case the cost of underinvestment is larger than the cost of low productive efficiency under weak incentives. 


\subsection{Private firm}

In case $v=1$, the owner's problem is

$$
\begin{array}{ll}
\max _{\{q, e, i\}} & {[p-C(e)-(F(e)+c q+k(i))+i-\delta](1+q)^{\alpha}} \\
\text { s.t. } & i \in[0, \bar{i}] .
\end{array}
$$

implying that $e=e^{*} ; i=i^{*}$ and

$$
q=\frac{\alpha}{c(1+\alpha)}\left[p-C\left(e^{*}\right)-\left[F\left(e^{*}\right)+k\left(i^{*}\right)\right]-\frac{c}{\alpha}\right] .
$$

Rearranging this expression, we get the treatment fee as a function of quality for $q>0$

$$
p(q)=\frac{(1+\alpha)}{\alpha} c q+C\left(e^{*}\right)+F\left(e^{*}\right)+k\left(i^{*}\right)+\frac{c}{\alpha}
$$

which is also equal to the total cost. For $q=0$, we get

$$
p(q=0)=C\left(e^{*}\right)+F\left(e^{*}\right)+k\left(i^{*}\right)
$$

which is just the lowest possible treatment fee such that the owner's participation constraint binds.

In case $v=0$, the owner's maximization problem is

$$
\begin{array}{ll}
\max _{\{q, e, i\}} & (p-C(e)+i-\delta)(1+q)^{\alpha} \\
\text { s.t. } & i \in[0, \bar{i}] .
\end{array}
$$

implying that $i=\bar{i}, e=\underline{e}$, and $q$ will be set to any value wished for by the public agency. Hence, the treatment fee where the owner's participation constraint binds is

$$
p=C(\underline{e})+\delta-\bar{i}
$$

Since the public agency pays the costs of production, total cost is

$$
T(q, v=0)=c q+C(\underline{e})+F(\underline{e})+k(\bar{i})-\bar{i}+\delta .
$$

The cost difference between $v=1$ and $v=0$ is thus

$$
\left[C\left(e^{*}\right)+F\left(e^{*}\right)+k\left(i^{*}\right)\right]-[C(\underline{e})+F(\underline{e})+k(\bar{i})-\bar{i}+\delta]<0
$$

for $q=0$ and

$$
\begin{aligned}
& {\left[\frac{(1+\alpha)}{\alpha} c q+C\left(e^{*}\right)+F\left(e^{*}\right)+k\left(i^{*}\right)+\frac{c}{\alpha}\right]-[c q+C(\underline{e})+F(\underline{e})+k(\bar{i})-\bar{i}+\delta] } \\
= & {\left[\frac{1}{\alpha} c q+\frac{c}{\alpha}+C\left(e^{*}\right)+F\left(e^{*}\right)+k\left(i^{*}\right)\right]-[C(\underline{e})+F(\underline{e})+k(\bar{i})-\bar{i}+\delta] }
\end{aligned}
$$

for $q>0$. Hence, though $v=1$ is always cheaper when quality is zero, it is cheaper for quality is above zero if and only if

$$
\frac{c}{\alpha}(q+1)<[C(\underline{e})+F(\underline{e})]-\left[C\left(e^{*}\right)+F\left(e^{*}\right)\right]+[k(\bar{i})-\bar{i}+\delta]-k\left(i^{*}\right),
$$

i.e., if the incentive cost for quality is smaller than the cost of weak incentives for cost reductions and overinvestment. It follows that for any level of quuality, there exists an overinvestment cost, $[k(\bar{i})-\bar{i}+\delta]-k\left(i^{*}\right)$ such that $v=1$ is optimal. That is, $v=1$ is optimal under private ownership when quality is unimportant, or when overinvestment is a substantial problem under cost contracting. 
Also note that when $v=1$ private ownership is superior to public ownership since, for $q>0$,

$$
\begin{aligned}
& {\left[\frac{(1+\alpha)}{\alpha} c q+\frac{c}{\alpha}+C\left(e^{*}\right)+F\left(e^{*}\right)+k\left(i^{*}\right)\right]-\left[\left(\frac{1+\alpha}{\alpha}\right) c q+\frac{c}{\alpha}+C\left(e^{*}\right)+F\left(e^{*}\right)+\delta\right] } \\
= & k\left(i^{*}\right)-\delta<0,
\end{aligned}
$$

and similarly for $q=0$. In contrast, public ownership is superior when $v=0$ since

$$
\begin{aligned}
& {[c q+C(\underline{e})+F(\underline{e})+k(\bar{i})-\bar{i}+\delta]-\left[c q+C(\underline{e})+F(\underline{e})+k\left(i^{*}\right)\right] } \\
= & {[k(\bar{i})-\bar{i}+\delta]-\left[k\left(i^{*}\right)\right]>0 . }
\end{aligned}
$$

\section{Time-variant treatment fees}

The analysis in the paper considered the case when the treatment fee was fixed throughout the treatment period. Now suppose instead that the public agency could commit to any vector of treatment fees $\mathbf{p}=$ $\left\{p_{1}, p_{2}, \ldots, p_{\infty}\right\}$. As is easily seen in (2.1), quality in the first treatment period is a function of $V_{2}$ which must be strictly above zero for the owner to have any incentives to put effort on quality. However, the treatment fee in the first period, $p_{1}$, does not affect incentives for quality. To see this, consider a contract where where $p$ is fixed from the second period and onwards. The owner's maximand can then be reformulated as

$$
\frac{p-F\left(t_{c}\right)-C(t)}{\lambda(q)}+\left(p_{1}-p\right) .
$$

That is, the producer's maximization problem with respect to quality and cost is the same as in (2.1) and unaffected by $p_{1}$. The fact that $p_{1}$ does not affect incentives for quality implies that $p_{1}$ can be set to neutralize the expected rent from subsequent period. If $p_{1}=F\left(e^{*}\right)+c q\left(V_{2}\right)-\left(1-\lambda\left(q\left(V_{2}\right)\right)\right) V_{2}$, we get from (2.1) that $V_{1}=0$, implying that the public agency can induce the owner both to give a truthful diagnosis and to invest in quality. In essence, the owner pays a lump-sum payment to the public agency during the first period, which he then recoups in future periods. There are however, several reasons for why contracts with such lump-sum payments may not be feasible in practice. First, a contract with $p_{1}<F\left(e^{*}\right)$ might not be feasible in case the producer is constrained by limited liability. Second, the use of lump-sum payments at the onset of treatment requires that each individual patient and treatment is easy to identify. In practice, the need to diagnose the needs of treatment is likely to arise over the course of treatment, at points in time which are hard to know beforehand. To renegotiate contracts on every such occassion would entail high transaction costs. Third, the fact that lump-sum transfers in effect implies that producers buy the right to treat a patient may not resonate well with social norms. Finally, if $B$ is private knowledge, a contract on low treatment fees at the beginning of treatment but high fees for subsequent periods might not be credible as public agencies with a low $B$ could exit from a relationship after the first period. In contrast, the public agency can credibly commit not to exit from a fixed-fee contract even if $B$ is private knowledge. ${ }^{1}$

\section{Proof of Lemma A1}

First consider the derivatives of $V^{p a}$ with respect to $B$. In the interior solution, we get

\footnotetext{
${ }^{1}$ To see this, note that the only reason for the public agency to exit a fixed-fee contract is that $B<p$ or that a hazard occurs. In case $p>0$, there is never in the interest of the public agency to enter a contract where $B<p$. In case $B>p$, the public agency wants to stay in the contractual relationship until a hazard occurs.
} 


$$
\begin{aligned}
\frac{\partial V^{p a}(B, p(B))}{\partial B}= & (1+q(p(B)))^{\alpha} \\
& +\left[\alpha(B-p(B))(1+q(p(B)))^{\alpha-1} \frac{\partial q}{\partial p}-(1+q(p(B)))^{\alpha}\right] \frac{\partial p}{\partial B} \\
= & (1+q(p(B)))^{\alpha} \\
& +\left[\alpha\left(B-\frac{B \alpha+F\left(e^{*}\right)+C\left(e^{*}\right)-c}{1+\alpha}\right) \frac{\partial q}{\partial p}(1+q(p(B)))^{\alpha-1}-(1+q(p(B)))^{\alpha}\right] \frac{\partial p}{\partial B} \\
= & (1+q(p(B)))^{\alpha} \\
& +\left[\frac{\alpha^{2}}{(1+\alpha)^{2} c}\left(B-F\left(e^{*}\right)-C\left(e^{*}\right)+c\right)(1+q(p(B)))^{\alpha-1}-(1+q(p(B)))^{\alpha}\right] \frac{\partial p}{\partial B} \\
= & (1+q(p(B)))^{\alpha} \\
& +\left[\left[q(p(B))+\frac{1+2 \alpha}{(1+\alpha)^{2}}+\frac{\alpha^{2}}{(1+\alpha)^{2}}\right](1+q(p(B)))^{\alpha-1}-(1+q(p(B)))^{\alpha}\right] \frac{\partial p}{\partial B} \\
= & (1+q(p(B)))^{\alpha} \\
& +\left[(q(p(B))+1)(1+q(p(B)))^{\alpha-1}-(1+q(p(B)))^{\alpha}\right] \frac{\partial p}{\partial B} \\
= & (1+q(p(B)))^{\alpha} \\
& +\left[(1+q(p(B)))^{\alpha}-(1+q(p(B)))^{\alpha}\right] \frac{\partial p}{\partial B} \\
= & (1+q(p(B)))^{\alpha}>1
\end{aligned}
$$

and

$$
\frac{\partial^{2} V^{p a}(B, p(B))}{\partial B^{2}}=\alpha(1+q(p(B)))^{\alpha-1} \frac{\partial q}{\partial p^{*}} \frac{\partial p^{*}}{\partial B}>0
$$

As $q(\underline{p})=0$, the derivative with respect to $B$ in the corner solution is

$$
\frac{\partial V^{p a}(B, \underline{p})}{\partial B}=(1+q(\underline{p}))^{\alpha}=1^{\alpha}=1 .
$$

The second derivative is zero.

Even if, as shown in the Appendix of the main paper, there exists an interior solution for all $B>\widetilde{B}^{o}$, we have that $V^{p a}(B, p)>V^{p a}\left(B, p^{*}(B)\right)$ when $B$ is close to $\widetilde{B}^{o}$. To see this, consider $B=\widetilde{B}^{o}+\varepsilon$ where $\varepsilon>0$ and the corresponding interior solution, $p^{*}$. Let $q\left(p^{*}\right)=q(p)+\delta=\delta$, implying that the gain in value of treatment from raising the price from $\underline{p}$ to $p^{*}$ is $(\widetilde{B}+\varepsilon) \delta$ which approach zero as $\varepsilon$ approach zero, whereas the cost difference $p^{*}-p$ approach $\widetilde{p}-p=\frac{c}{\alpha}$ from above. However, as the derivative of $V^{p a}$ with respect to $B$ is always higher in the interior solution, and the difference is increasing in $B$, there exists a unique value $B^{o}$ such that

$$
V^{p a}\left(B^{o}, p^{*}\left(B^{o}\right)\right)=V^{p a}\left(B^{o}, \underline{p}\right) .
$$

When $B=B^{o}$, the public agency is thus indifferent between $\underline{p}$ and $p^{*}$. For $B<B^{o}, \underline{p}$ strictly dominates $p^{*}$, whereas $p^{*}$ strictly dominates $\underline{p}$ when $B>B^{\circ}$. 


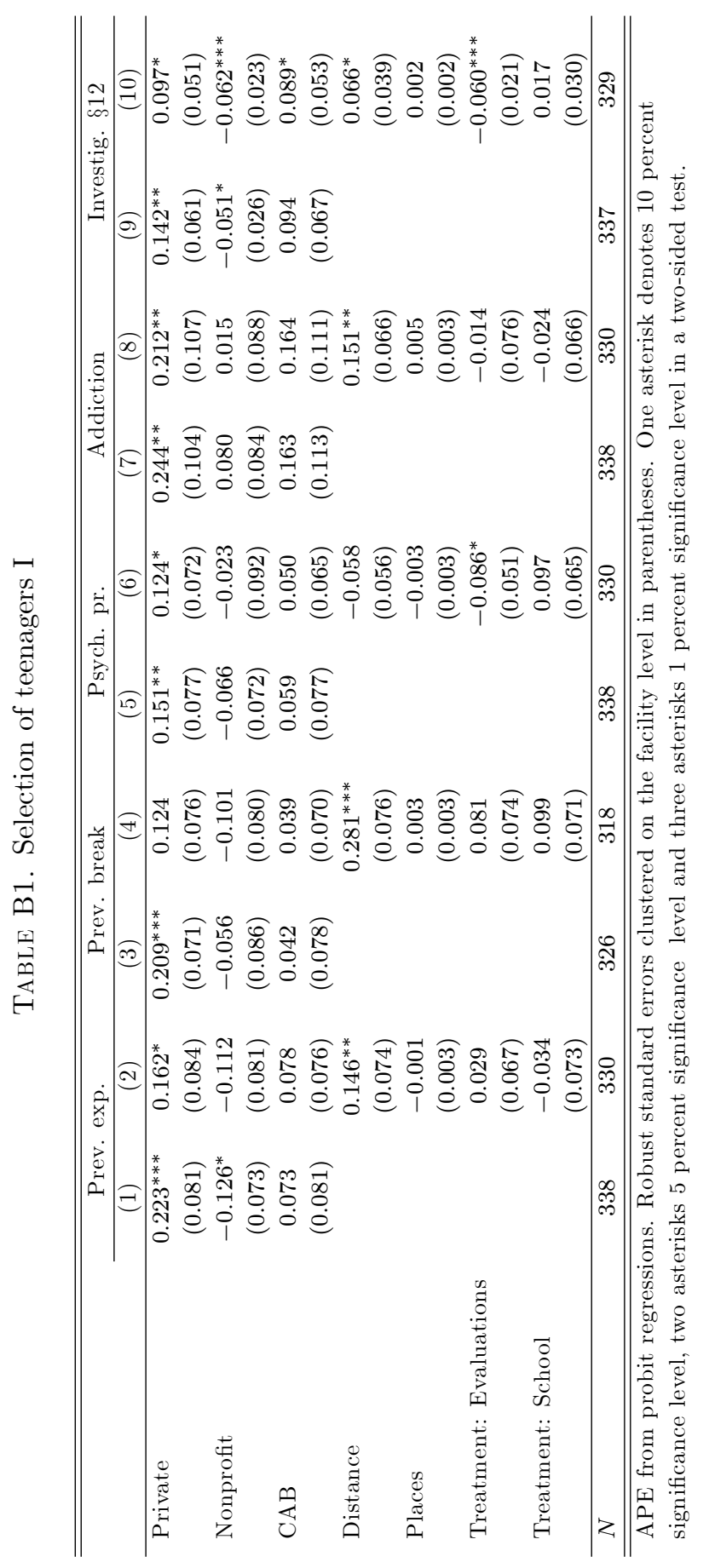




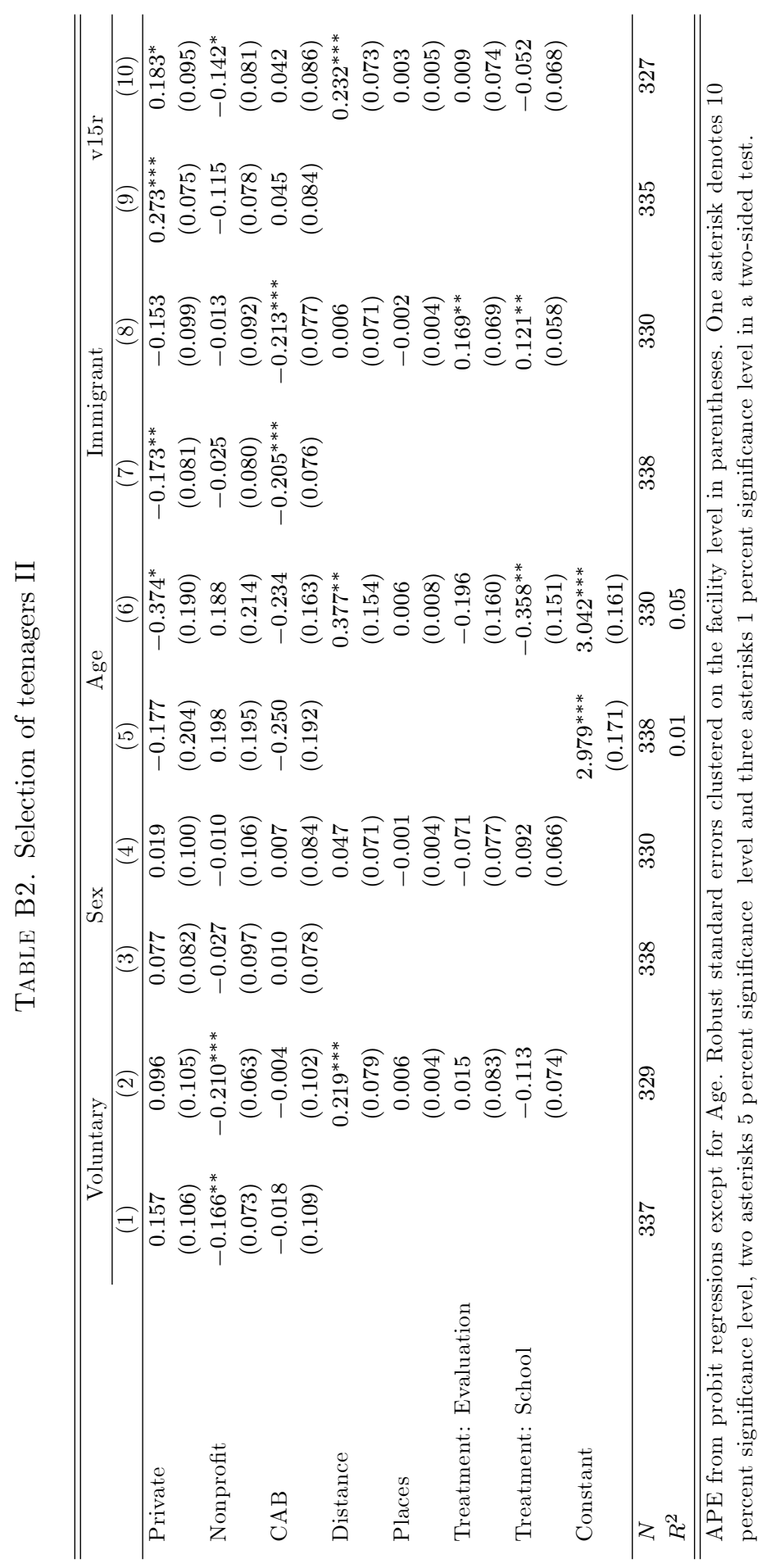




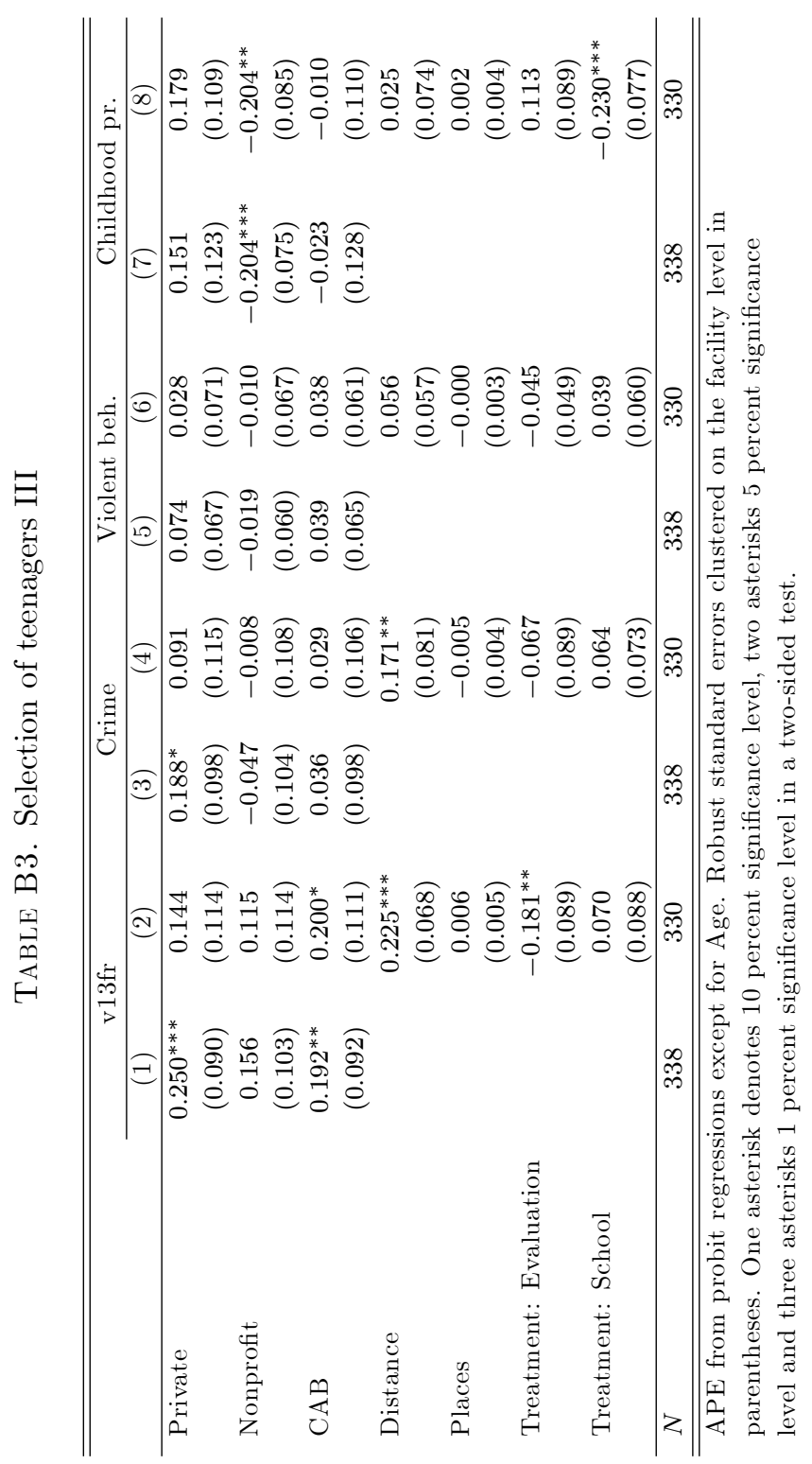




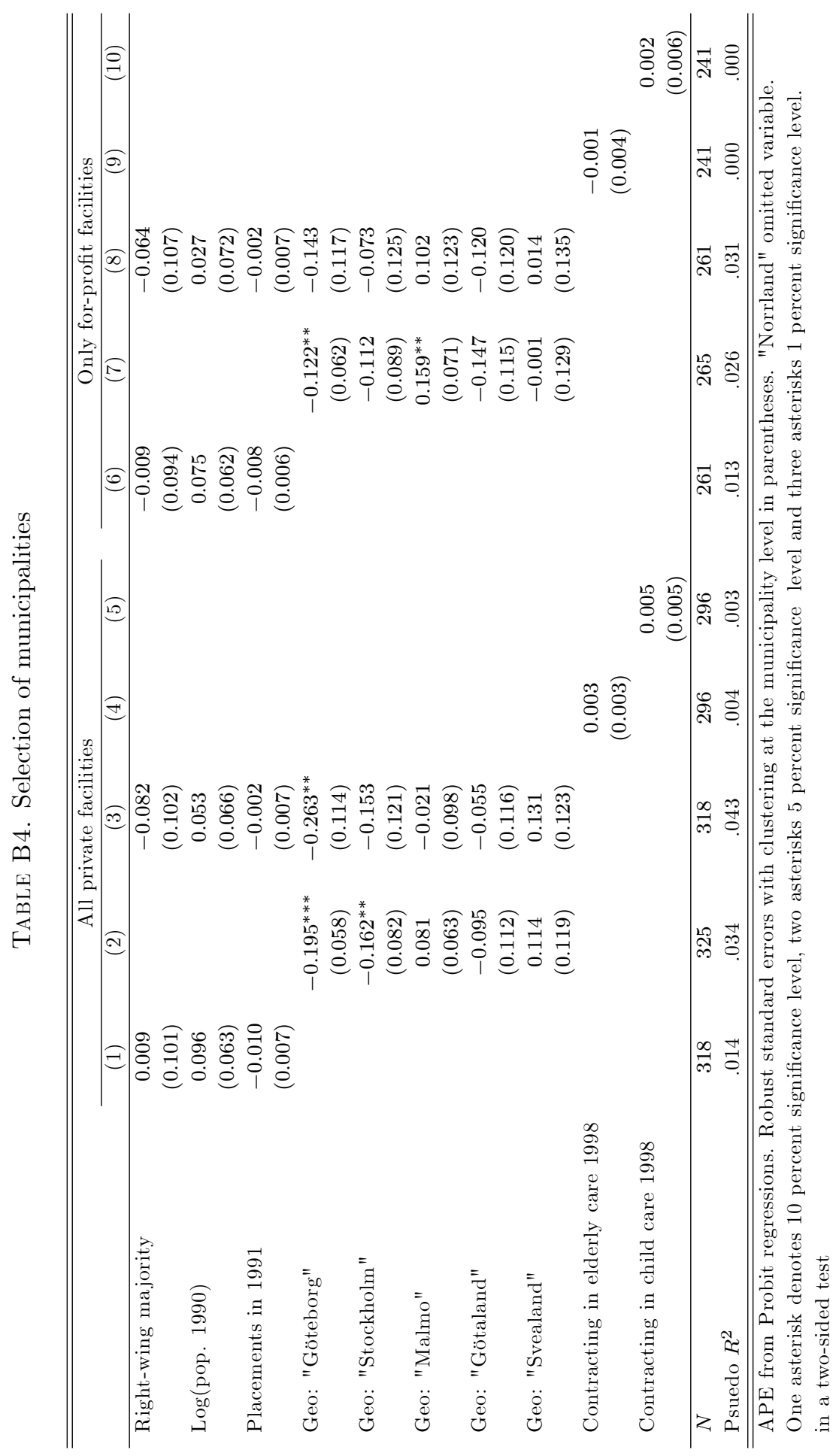


TABLE B5. Robustness checks, cost

\begin{tabular}{|c|c|c|c|}
\hline & \multicolumn{3}{|l|}{ Price (SEK) } \\
\hline & (1) OLS & (2) OLS & (3) OLS \\
\hline Constant & $\begin{array}{c}51,360^{* * *} \\
(15,969)\end{array}$ & $\begin{array}{c}47,464^{* * *} \\
(12,108)\end{array}$ & $\begin{array}{c}20,086 \\
(16,960)\end{array}$ \\
\hline Private & $\begin{array}{c}-25,742^{* *} \\
(10,011)\end{array}$ & $\begin{array}{c}-14,927^{*} \\
(7,638)\end{array}$ & $\begin{array}{c}-16,465^{* *} \\
(7,774)\end{array}$ \\
\hline Personnel density & $\begin{array}{c}2,860 \\
(6,953)\end{array}$ & $\begin{array}{l}9,726^{* *} \\
(4,030)\end{array}$ & $\begin{array}{c}10,540^{* * *} \\
(3,922)\end{array}$ \\
\hline Private*Personnel density & $\begin{array}{c}28,052^{* * *} \\
(7,697)\end{array}$ & $\begin{array}{c}21,696^{* * *} \\
(5,732)\end{array}$ & $\begin{array}{c}21,675^{* * *} \\
(5,652)\end{array}$ \\
\hline Nonprofit & $\begin{array}{l}-3,201 \\
(6,908)\end{array}$ & $\begin{array}{c}1,619 \\
(4,672)\end{array}$ & $\begin{array}{c}855 \\
(4,379)\end{array}$ \\
\hline County & $\begin{array}{l}-19,123 \\
(17,982)\end{array}$ & $\begin{array}{l}-3,549 \\
(4,598)\end{array}$ & $\begin{array}{c}981 \\
(4,593)\end{array}$ \\
\hline Nonprofit*Personnel density & $\begin{array}{c}4,454 \\
(9,056)\end{array}$ & & \\
\hline County*Personnel density & $\begin{array}{c}12,903 \\
(12,107)\end{array}$ & & \\
\hline Private*Right wing & & $\begin{array}{c}-10,982^{* *} \\
(4,827)\end{array}$ & \\
\hline Private* $\log ($ pop. 1990) & & & $\begin{array}{c}-4,311^{* *} \\
(1,938)\end{array}$ \\
\hline Teenager characteristics & Yes & Yes & Yes \\
\hline Facility characteristics & Yes & Yes & Yes \\
\hline Municipality characteristics & Yes & Yes & Yes \\
\hline Municipality FE & No & No & No \\
\hline$N$ & 258 & 258 & 258 \\
\hline$R^{2}$ & 0.58 & 0.59 & 0.59 \\
\hline
\end{tabular}

Robust standard errors clustered on the facility level in parentheses. One asterisk denotes 10 percent significance level, two asterisks 5 percent significance level and three asterisks 1 percent significance level in a two-sided test. 
TABle B6. Facilities with a personnel density of 0.8 or more

\begin{tabular}{lccccc}
\hline \hline \multirow{2}{*}{ Variable } & Price (SEK) & & & \\
\cline { 2 - 6 } Constant & $(1)$ OLS & $(2)$ OLS & $(3)$ OLS & $(4)$ OLS & $(5)$ OLS \\
\hline \multirow{2}{*}{ Private } & $22,348^{* *}$ & $18,000^{*}$ & $22,539^{* *}$ & $54,571^{* * *}$ & $25,827^{* *}$ \\
& $(9,841)$ & $(10,308)$ & $(9,705)$ & $(11,042)$ & $(12,248)$ \\
Personnel density & $-4,348$ & 2,896 & $-6,966$ & $-18,729$ & $-13,632$ \\
& $(13,017)$ & $(13,103)$ & $(13,102)$ & $(13,017)$ & $(17,085)$ \\
Private*Pers. density & $19,994^{* * *}$ & $24,109^{* * *}$ & $17,754^{* * *}$ & $12,421^{* *}$ & 13,710 \\
& $(6,584)$ & $(6,591)$ & $(6,095)$ & $(5,390)$ & $(8,371)$ \\
Nonprofit & 12,710 & 8,490 & $16,860^{* *}$ & $22,487^{* *}$ & 20,306 \\
& $(8,589)$ & $(8,629)$ & $(8,076)$ & $(8,829)$ & $(12,306)$ \\
& $-1,041$ & 776 & 4,375 & 7,460 & $19,197^{* *}$ \\
Teenager ch. & $(6,326)$ & $(6,476)$ & $(6,128)$ & $(7,227)$ & $(8,612)$ \\
Facility ch. & No & Yes & Yes & Yes & Yes \\
Municipality ch. & No & No & Yes & Yes & Yes \\
Municipality FE & No & No & No & Yes & No \\
\hline$N$ & No & No & No & No & Yes \\
$R^{2}$ & 235 & 226 & 226 & 202 & 206 \\
\hline \hline
\end{tabular}

Robust standard errors clustered on the facility level in parentheses. One asterisk denotes 10 percent significance level, two asterisks 5 percent significance level and three asterisks 1 percent significance level in a one-sided test. 
Table B7. Excluding County facilities

\begin{tabular}{lccccc}
\hline \hline \multirow{5}{*}{ Constant } & Price (SEK) & & & \\
\cline { 2 - 6 } & $(1)$ OLS & $(2)$ OLS & $(3)$ OLS & $(4)$ OLS & $(5)$ OLS \\
\hline \multirow{2}{*}{ Private } & $22,757^{* * *}$ & $14,554^{*}$ & $32,698^{* *}$ & $75,328^{* * *}$ & $44,864^{* *}$ \\
& $(7,573)$ & $(8,723)$ & $(14,280)$ & $(28,244)$ & $(21,470)$ \\
Personnel density & $-5,942$ & -899 & $-18,547$ & $-22,128$ & $-27,784$ \\
& $(8,083)$ & $(9,132)$ & $(16,088)$ & $(18,199)$ & $(20,190)$ \\
Private*Pers. dens. & $20,320^{* * *}$ & $24,925^{* * *}$ & 10,727 & 8,038 & -637 \\
& $(4,588)$ & $(5,209)$ & $(12,529)$ & $(16,351)$ & $(18,641)$ \\
Nonprofit & $13,004^{* *}$ & 7,039 & 21,869 & 23,91 & $34,663^{*}$ \\
& $(5,574)$ & $(6,409)$ & $(13,424)$ & $(17,240)$ & $(18,533)$ \\
& $-1,956$ & -378 & 1,236 & 1,67 & 10,823 \\
Teenager ch. & $(4,168)$ & $(4,251)$ & $(3,986)$ & $(4,459)$ & $(9,635)$ \\
Facility ch. & No & Yes & Yes & Yes & Yes \\
Municipality ch. & No & No & Yes & Yes & Yes \\
Municipality FE & No & No & No & Yes & No \\
\hline Observations & No & No & No & No & Yes \\
R-squared & 175 & 166 & 165 & 145 & 148 \\
\hline \hline Robust standard errors clustered on the facility level in parentheses. One asterisk \\
denotes 10 percent significance level, two asterisks 5 percent significance level \\
and three asterisks 1 percent significance level in a one-sided test. &
\end{tabular}


TABLE B8. Controlling for insiders and outsiders

\begin{tabular}{lccccc}
\hline \hline & Price (SEK) & & & \\
\cline { 2 - 6 } & $(1)$ OLS & $(2)$ OLS & $(3)$ OLS & $(4)$ OLS & $(5)$ OLS \\
\hline Constant & $29,149^{* * *}$ & $26,752^{* * *}$ & $26,749^{* * *}$ & $37,777^{* * *}$ & $21,347^{*}$ \\
& $(8,542)$ & $(9,681)$ & $(8,131)$ & $(13,379)$ & $(12,813)$ \\
Private & $-12,334$ & $-9,816$ & $-10,36$ & $-13,014$ & $-4,736$ \\
& $(8,996)$ & $(9,956)$ & $(8,455)$ & $(8,334)$ & $(12,313)$ \\
Personnel density & $15,477^{* *}$ & $17,582^{* * *}$ & $13,982^{* * *}$ & $11,045^{* * *}$ & $15,460^{*}$ \\
& $(5,936)$ & $(6,505)$ & $(4,808)$ & $(4,192)$ & $(8,895)$ \\
Private*Pers. dens & $17,847^{* * *}$ & $15,577^{* *}$ & $18,537^{* * *}$ & $20,224^{* * *}$ & $16,057^{*}$ \\
& $(6,725)$ & $(7,447)$ & $(5,690)$ & $(5,907)$ & $(9,194)$ \\
Nonprofit & $-1,956$ & $-1,595$ & 349 & 1,206 & 9,299 \\
& $(4,162)$ & $(4,251)$ & $(4,015)$ & $(4,843)$ & $(7,578)$ \\
Outsider: Municipality & 3,214 & 4,884 & 8,053 & $9,445^{*}$ & 10,672 \\
& $(4,755)$ & $(5,159)$ & $(5,991)$ & $(5,152)$ & $(7,336)$ \\
Outsider: County & 2,578 & 1,916 & -318 & 2,120 & -924 \\
& $(4,236)$ & $(4,880)$ & $(4,161)$ & $(4,248)$ & $(6,506)$ \\
\hline Teenager ch. & No & Yes & Yes & Yes & Yes \\
Facility ch. & No & No & Yes & Yes & Yes \\
Municipality ch. & No & No & No & Yes & No \\
Municipality FE & No & No & No & No & Yes \\
\hline Observations & 302 & 289 & 288 & 258 & 263 \\
R-squared & 0.36 & 0.39 & 0.50 & 0.57 & 0.83 \\
\hline \hline Robist & & &
\end{tabular}

Robust standard errors clustered on the facility level in parentheses. One asterisk denotes 10 percent significance level, two asterisks 5 percent significance level and three asterisks 1 percent significance level in a one-sided test.

TABLE B9. Cost and personnel density in public facilities

\begin{tabular}{lcccc}
\hline \hline & County & & Municipality & \\
& Mean & Std & Mean & Std \\
\hline Cost & 51,100 & 15,040 & 50,590 & 10,049 \\
Personnel density & 1.505 & .274 & 1.517 & .831 \\
\hline \hline
\end{tabular}


TABLE B10. Excluding non-profit facilities

\begin{tabular}{lccccc}
\hline \hline \multirow{5}{*}{ Treatment breakdown } & & \\
\cline { 2 - 6 } & $(1)$ OLS & $(2)$ OLS & $(3)$ OLS & $(4)$ OLS & $(5)$ OLS \\
\hline Private & $.265^{* * *}$ & $.240^{* * *}$ & $.207^{* *}$ & $.222^{* *}$ & 0.212 \\
County & $(.073)$ & $(.092)$ & $(.098)$ & $(.115)$ & $(0.194)$ \\
& .091 & .031 & .033 & .002 & -0.137 \\
Private*Violence & $.070)$ & $(.074)$ & $(.077)$ & $(.105)$ & $(0.166)$ \\
& & $-.368^{* * *}$ & $-.379^{* * *}$ & $-.290^{* *}$ & $-0.463^{* *}$ \\
Private*Pr. break & & $(.156)$ & $(.159)$ & $(.171)$ & $(0.203)$ \\
& & -.100 & -.142 & -.133 & -0.187 \\
Constant & $(.130)$ & $(.135)$ & $(.155)$ & $(0.213)$ \\
& $.187^{* * *}$ & -.025 & .072 & -.167 & 0.304 \\
Teenager ch. & $(.054)$ & $(.104)$ & $(.107)$ & $(.442)$ & $(0.469)$ \\
Facility ch. & No & Yes & Yes & Yes & Yes \\
Municipality ch. & No & No & Yes & Yes & Yes \\
Municipality FE & No & No & No & Yes & No \\
\hline$N$ & 287 & 275 & 267 & 240 & 244 \\
$R^{2}$ & .05 & .23 & .24 & .29 & 0.60 \\
\hline \hline Robust standard errors clustered on the facility level in parentheses. One asterisk \\
denotes 10 percent significance level, two asterisks 5 percent significance level \\
and three asterisks 1 percent significance level in a one-sided test.
\end{tabular}

TABLE B11. Breakdowns, control for planned duration

\begin{tabular}{lccccc}
\hline \hline & \multicolumn{3}{c}{ Treatment breakdown } & \\
\cline { 2 - 5 } Constant & $(1)$ OLS & $(2)$ OLS & $(3)$ OLS & $(4)$ OLS & $(5)$ OLS \\
& .072 & $-.282^{* *}$ & -.205 & -1.288 & -.711 \\
Private & $.093)$ & $(.162)$ & $(.185)$ & $(.666)$ & $(1.287)$ \\
& .144 & $.329^{* *}$ & $.289^{* *}$ & $.358^{*}$ & .007 \\
Nonprofit & $(.135)$ & $(.150)$ & $(.166)$ & $(.264)$ & $(.955)$ \\
& -.106 & -.126 & -.139 & $-.374^{*}$ & .278 \\
County & $(.118)$ & $(.154)$ & $(.179)$ & $(.212)$ & $(.601)$ \\
& .145 & .116 & .138 & .072 & .038 \\
Planned duration & $(.110)$ & $(.104)$ & $(.109)$ & $(.199)$ & $(.576)$ \\
& .608 & .414 & .223 & .259 & 1.312 \\
Private*Planned duration (norm.) & $(.511)$ & $(.421)$ & $(.458)$ & $(.427)$ & $(2.069)$ \\
& .195 & -.006 & .002 & -.554 & -1.691 \\
Private*Violence & $(.709)$ & $(.807)$ & $(.827)$ & $(1.012)$ & $(2.625)$ \\
Private*Prevous breakdown & & $-.565^{* *}$ & $-.578^{* *}$ & $-.699^{* *}$ & $-.840^{*}$ \\
& & $(.252)$ & $(.246)$ & $(.307)$ & $(.645)$ \\
Teenager ch. & & -.208 & -.215 & -.176 & .537 \\
Facility ch. & & $(.217)$ & $(.248)$ & $(.282)$ & $(.584)$ \\
Municipality ch. & No & Yes & Yes & Yes & Yes \\
Municipality FE & No & No & Yes & Yes & Yes \\
\hline$N$ & No & No & No & Yes & No \\
$R^{2}$ & No & No & No & No & Yes \\
\hline \hline
\end{tabular}

Robust standard errors clustered on the facility level in parentheses. One asterisk denotes 10 percent significance level, two asterisks 5 percent significance level and three asterisks 1 percent significance level in a one-sided test, except Nonprofit which refers to a two-sided test. Coefficients for expected duration of treatment multiplied ny 100 . The interaction term between private ownership and planned duration of treatment is normalized around the mean planned duration of treatment in private facilities. 
TABLE B12. Troublesome vs. non-troublesome teenagers

\begin{tabular}{lcccccc}
\hline \hline \multirow{2}{*}{$\%$} & \multicolumn{2}{c}{ Public } & & \multicolumn{2}{c}{ Private } \\
\cline { 2 - 3 } \cline { 6 - 7 } & Tr. & Non-tr. & & Tr. & Non-tr. \\
\hline Psychological problems & 20.7 & 16.3 & & 27.4 & 28.0 \\
Addiction & 37.9 & 22.8 & & 51.2 & 34.1 \\
Investigated at $\S 12-$-home & 10.3 & 4.1 & & 17.1 & 4.9 \\
Non-voluntary placement & 29.3 & 19.5 & & 48.8 & 22.2 \\
Criminal behavior & 44.8 & 28.5 & & 58.3 & 34.1 \\
Placed in care because of own behavior & 67.2 & & 47.2 & & 70.2 & 67.1 \\
Previous experience of youth care & 57.8 & 17.1 & & 76.4 & 21.1 \\
Previously in youth- or foster care & 51.7 & 10.8 & & 68.7 & 24.4 \\
Problems at home during childhood & 58.6 & 49.6 & & 69.0 & 52.4 \\
\hline \hline
\end{tabular}

TABLE B13. Breakdowns not on the facility's initiative

\begin{tabular}{|c|c|c|c|c|c|}
\hline & \multicolumn{5}{|c|}{ Treatment breakdown } \\
\hline & (1) OLS & (2) OLS & (3) OLS & (4) OLS & (5) OLS \\
\hline \multirow[t]{2}{*}{ Constant } & $.114^{* * *}$ & -.006 & .033 & -.207 & -0.181 \\
\hline & $(.047)$ & $(.096)$ & $(.101)$ & $(.372)$ & $(0.311)$ \\
\hline \multirow[t]{2}{*}{ Private } & $.250^{* * *}$ & $.184^{* *}$ & $.191^{* *}$ & $.182^{*}$ & 0.198 \\
\hline & $(.071)$ & $(.083)$ & $(.090)$ & $(.116)$ & $(0.183)$ \\
\hline \multirow[t]{2}{*}{ Nonprofit } & $-.242^{* * *}$ & $-.194^{* * *}$ & $-.179^{* *}$ & $-.230^{* * *}$ & $-0.311^{* *}$ \\
\hline & $(.068)$ & $(.071)$ & $(.072)$ & $(.085)$ & $(0.156)$ \\
\hline \multirow[t]{2}{*}{ County } & .052 & .025 & .037 & -.015 & -0.049 \\
\hline & $(.059)$ & $(.068)$ & $(.069)$ & $(.107)$ & $(0.171)$ \\
\hline \multirow[t]{2}{*}{ Private*Violence } & & $-.264^{* *}$ & $-.247^{*}$ & $-.269^{* *}$ & $-0.443^{* *}$ \\
\hline & & $(.154)$ & $(.160)$ & $(.160)$ & $(0.203)$ \\
\hline \multirow[t]{2}{*}{ Private*Pr. break } & & .117 & .083 & .041 & 0.094 \\
\hline & & $(.125)$ & $(.132)$ & $(.150)$ & $(0.229)$ \\
\hline Teenager ch. & No & Yes & Yes & Yes & Yes \\
\hline Facility ch. & No & No & Yes & Yes & Yes \\
\hline Municipality ch. & No & No & No & Yes & No \\
\hline Municipality FE & No & No & No & No & Yes \\
\hline$N$ & 288 & 274 & 267 & 245 & 249 \\
\hline$R^{2}$ & .06 & .23 & .23 & .27 & 0.62 \\
\hline
\end{tabular}

The standard errors within parentheses have been corrected for clustering at the facility level and heteroskedasticity. One asterisk denotes 10 percent significance level, two asterisks 5 percent significance level and three asterisks 1 percent significance level in a one-sided test, except for Nonprofit and CAB which refers to a two-sided test. 
TABle B14. Additional control variables

\begin{tabular}{|c|c|c|c|c|}
\hline & \multicolumn{4}{|c|}{ Duration (months) } \\
\hline & (1) OLS & (2) OLS & (3) OLS & (4) OLS \\
\hline Constant & $\begin{array}{c}3.872 \\
(11.198)\end{array}$ & $\begin{array}{c}9.854 \\
(6.292)\end{array}$ & $\begin{array}{c}17.704 \\
(12.087)\end{array}$ & $\begin{array}{c}18.598^{* *} \\
(7.429)\end{array}$ \\
\hline Private & $\begin{array}{c}12.581^{* * *} \\
(3.716)\end{array}$ & $\begin{array}{c}11.962^{*} \\
(6.945)\end{array}$ & $\begin{array}{c}14.355^{* * *} \\
(3.553)\end{array}$ & $\begin{array}{l}14.000 \\
(8.630)\end{array}$ \\
\hline Nonprofit & $\begin{array}{l}-3.672 \\
(3.335)\end{array}$ & $\begin{array}{l}-0.344 \\
(4.610)\end{array}$ & $\begin{array}{l}-4.398 \\
(3.449)\end{array}$ & $\begin{array}{l}-1.998 \\
(4.721)\end{array}$ \\
\hline County & $\begin{array}{c}0.953 \\
(2.626)\end{array}$ & $\begin{array}{l}-0.424 \\
(5.573)\end{array}$ & $\begin{array}{c}2.157 \\
(2.937)\end{array}$ & $\begin{array}{c}1.592 \\
(7.741)\end{array}$ \\
\hline Personnel density & $\begin{array}{c}2.239 \\
(1.452)\end{array}$ & $\begin{array}{c}0.805 \\
(1.692)\end{array}$ & & \\
\hline Breakdown & $\begin{array}{c}-8.132^{* * *} \\
(1.771)\end{array}$ & $\begin{array}{c}-9.856^{* * *} \\
(2.673)\end{array}$ & $\begin{array}{c}-7.578^{* * *} \\
(1.961)\end{array}$ & $\begin{array}{c}-9.135^{* * *} \\
(2.739)\end{array}$ \\
\hline Cost (in $1000 \mathrm{SEK}$ ) & & & $\begin{array}{l}-0.066 \\
(0.058)\end{array}$ & $\begin{array}{l}-0.101 \\
(0.078)\end{array}$ \\
\hline Teenager charact. & Yes & Yes & Yes & Yes \\
\hline Facility charact. & Yes & Yes & Yes & Yes \\
\hline Municipality charact. & Yes & No & Yes & No \\
\hline Municipality FE & No & Yes & No & Yes \\
\hline Full set of treatment options & Yes & Yes & No & No \\
\hline Observations & 277 & 282 & 256 & 261 \\
\hline R-squared & 0.42 & 0.69 & 0.40 & 0.70 \\
\hline
\end{tabular}

Vector of teenager characteristics includes interaction effects between private ownership and troublesome teenagers. The standard errors within parentheses have been corrected for clustering at the facility level and heteroskedasticity. One asterisk denotes 10 percent significance level, two asterisks 5 percent significance level and three asterisks 1 percent significance level in a two-sided test. 
TABLE B15. Excess duration of treatment

\begin{tabular}{|c|c|c|c|c|c|c|c|}
\hline \multirow[b]{3}{*}{ Variable } & \multicolumn{7}{|c|}{ Duration (months) } \\
\hline & \multicolumn{4}{|c|}{ Original data } & \multicolumn{3}{|c|}{ Imputed values } \\
\hline & (1) OLS & (2) OLS & (3) OLS & (4) OLS & (5) OLS & (6) OLS & (7) OLS \\
\hline \multirow{2}{*}{ Constant } & $4.640^{* *}$ & $4.951^{* *}$ & 3.240 & -18.783 & 2.299 & 3.186 & 8.372 \\
\hline & $(2.026)$ & $(2.091)$ & $(5.975)$ & $(19.197)$ & $(2.246)$ & $(2.168)$ & $(10.155)$ \\
\hline \multirow[t]{2}{*}{ Private } & $8.272^{* *}$ & $8.983^{* *}$ & $9.466^{*}$ & -0.985 & $11.975^{* * *}$ & $13.822^{* * *}$ & $14.262^{* * *}$ \\
\hline & $(3.661)$ & $(3.627)$ & $(4.944)$ & $(6.014)$ & $(2.216)$ & $(2.162)$ & (3.130) \\
\hline \multirow[t]{2}{*}{ Nonprofit } & 0.228 & -0.324 & 1.652 & 3.781 & -2.690 & $-3.764^{*}$ & $-4.833^{*}$ \\
\hline & $(3.582)$ & $(3.492)$ & $(4.563)$ & $(5.493)$ & $(2.175)$ & $(2.104)$ & $(2.478)$ \\
\hline \multirow[t]{2}{*}{ County } & -0.529 & 0.205 & 2.185 & -4.889 & 1.454 & 2.124 & 1.800 \\
\hline & (1.908) & $(2.035)$ & $(2.347)$ & $(4.914)$ & $(2.149)$ & $(2.073)$ & $(2.794)$ \\
\hline \multirow[t]{2}{*}{ Breakdown } & & $-5.103^{*}$ & $-5.998^{* *}$ & $-6.855^{* *}$ & & $-7.708^{* * *}$ & $-7.488^{* * *}$ \\
\hline & & $(2.721)$ & $(2.953)$ & $(2.976)$ & & $(1.466)$ & $(1.716)$ \\
\hline \multirow[t]{2}{*}{ Planned dur. } & $0.516^{* * *}$ & $0.552^{* * *}$ & $0.420^{* * *}$ & $0.366^{* * *}$ & $.546^{* * *}$ & $.589^{* * *}$ & $.371^{* * *}$ \\
\hline & $(0.118)$ & $(0.115)$ & $(0.105)$ & $(0.103)$ & $(.104)$ & $(.101)$ & $(.108)$ \\
\hline Teenager ch. & No & No & Yes & Yes & No & No & Yes \\
\hline Facility ch. & No & No & Yes & Yes & No & No & Yes \\
\hline Munic. ch. & No & No & No & Yes & No & No & Yes \\
\hline Munic. FE & No & No & No & No & No & No & No \\
\hline$p: \widehat{\beta}_{2}-\widehat{\beta}_{5}$ & & & & & .00 & .00 & .00 \\
\hline$N$ & 103 & 103 & 95 & 86 & 341 & 341 & 284 \\
\hline$R^{2}$ & 0.36 & 0.39 & 0.59 & 0.65 & .21 & .27 & .42 \\
\hline
\end{tabular}

Vector of teenager characteristics includes interaction effects between private ownership and troublesome teenagers. The standard errors within parentheses have been corrected for clustering at the facility level and heteroskedasticity for (1) to (4), but only not clustered for (5) to (8). One asterisk denotes 10 percent significance level, two asterisks 5 percent significance level and three asterisks 1 percent significance level in a two-sided test. 
TABLE B16. PT outcomes I, teenagers with one placement

\begin{tabular}{|c|c|c|c|c|c|c|c|c|}
\hline & \multicolumn{4}{|c|}{ Social assistance } & \multicolumn{4}{|c|}{ Education } \\
\hline & (1) OLS & (2) OLS & (3) OLS & (4) OLS & (5) OLS & (6) OLS & (7) OLS & (8) OLS \\
\hline \multirow[t]{2}{*}{ Constant } & $.353^{* * *}$ & $.264^{*}$ & -.319 & -.165 & $.676^{* * *}$ & $.800^{* * *}$ & $1.114^{* *}$ & $1.102^{* *}$ \\
\hline & $(.072)$ & $(.140)$ & $(.540)$ & $(.513)$ & $(.080)$ & $(.177)$ & $(.552)$ & $(0.539)$ \\
\hline \multirow[t]{2}{*}{ Private } & -.119 & $-.214^{*}$ & -.146 & -.107 & -.005 & -.159 & -.125 & -0.447 \\
\hline & $(.089)$ & $(.111)$ & $(.159)$ & $(.287)$ & $(.100)$ & $(.139)$ & $(.147)$ & $(0.279)$ \\
\hline \multirow[t]{2}{*}{ Nonprofit } & .073 & .043 & .054 & .134 & -.005 & -.059 & -.050 & 0.320 \\
\hline & $(.098)$ & $(.107)$ & $(.119)$ & $(.138)$ & $(.098)$ & $(.106)$ & $(.114)$ & $(0.199)$ \\
\hline \multirow[t]{2}{*}{ County } & & -.171 & -.154 & -.040 & -.049 & -.138 & -.102 & -0.249 \\
\hline & () & $(.105)$ & $(.152)$ & $(.275)$ & $(.094)$ & $(.114)$ & $(.127)$ & $(0.250)$ \\
\hline \multirow[t]{2}{*}{ Private*Violence } & & .011 & -.036 & -.192 & & .070 & .090 & .208 \\
\hline & & $(.180)$ & $(.163)$ & $(.227)$ & & $(.171)$ & $(.192)$ & $(0.334)$ \\
\hline \multirow[t]{2}{*}{ Private*Pr. break } & & .054 & .076 & -.023 & & -.190 & -.151 & .372 \\
\hline & & $(.180)$ & $(.192)$ & $(.383)$ & & $(.143)$ & $(.157)$ & $(0.306)$ \\
\hline Teenager ch. & No & Yes & Yes & Yes & No & Yes & Yes & Yes \\
\hline Facility ch. & No & No & Yes & Yes & No & No & Yes & Yes \\
\hline Municipality ch. & No & No & Yes & No & No & No & Yes & No \\
\hline Municipality FE & No & No & No & Yes & No & No & No & Yes \\
\hline$N$ & 224 & 195 & 191 & 195 & 223 & 194 & 190 & 194 \\
\hline$R^{2}$ & .01 & .17 & .23 & 0.66 & .00 & .16 & .18 & 0.62 \\
\hline
\end{tabular}

Robust standard errors clustered on the facility level in parentheses. One asterisk denotes 10 percent significance level, two asterisks 5 percent significance level and three asterisks 1 percent significance level in a two-sided test. 
TABLE B17. PT outcomes II, teenagers with one placement

\begin{tabular}{lcccccccc}
\hline \hline & \multicolumn{7}{c}{ Convictions } & \multicolumn{7}{c}{ Imprisonment } \\
\hline & $(1)$ OLS & $(2)$ OLS & $(3)$ OLS & $(4)$ OLS & $(5)$ & $(6)$ & $(7)$ & $(8)$ \\
\hline Constant & $.471^{* * *}$ & .296 & .195 & .263 & $.118^{* *}$ & .030 & -.753 & -.132 \\
Private & $.073)$ & $(.138)$ & $(.474)$ & $(.416)$ & $(.047)$ & $(.136)$ & $(.503)$ & $(.427)$ \\
& .045 & .075 & .167 & -.038 & .054 & .022 & -.018 & .033 \\
Nonprofit & $(.098)$ & $(.108)$ & $(.143)$ & $(.274)$ & $(.069)$ & $(.108)$ & $(.123)$ & $(.202)$ \\
& .049 & .044 & .051 & -.041 & .085 & .087 & .068 & .109 \\
County & $(.116)$ & $(.113)$ & $(.117)$ & $(.229)$ & $(.089)$ & $(.102)$ & $(.106)$ & $(.202)$ \\
& .024 & .009 & .109 & -.246 & .078 & .041 & -.005 & -.116 \\
Private*Violence & $(.095)$ & $(.080)$ & $(.129)$ & $(.248)$ & $(.068)$ & $(.090)$ & $(.113)$ & $(.208)$ \\
& & $-.267^{* *}$ & $-.214^{*}$ & $-.351^{*}$ & & $-.340^{* *}$ & $-.308^{* *}$ & $-.484^{* *}$ \\
Private*Pr. break & & $(.159)$ & $(.165)$ & $(.201)$ & & $(.163)$ & $(.166)$ & $(.238)$ \\
& & $-.347^{* *}$ & $-.364^{* *}$ & -.407 & & .007 & .076 & -.028 \\
& & $(.196)$ & $(.195)$ & $(.307)$ & & $(.144)$ & $(.138)$ & $(.315)$ \\
\hline Teenager ch. & No & Yes & Yes & Yes & No & Yes & Yes & Yes \\
Facility ch. & No & No & Yes & Yes & No & No & Yes & Yes \\
Municipality ch. & No & No & Yes & No & No & No & Yes & No \\
Municipality FE & No & No & No & Yes & No & No & No & Yes \\
\hline$N$ & 224 & 195 & 191 & 195 & 224 & 195 & 191 & 195 \\
$R^{2}$ & .00 & .32 & .35 & .72 & .01 & .31 & .37 & .69 \\
\hline \hline
\end{tabular}

Robust standard errors clustered on the facility level in parentheses. One asterisk denotes 10 percent significance level, two asterisks 5 percent significance level and three asterisks 1 percent significance level in a two-sided test, except for the interaction terms which refer to a one-sided test. 
TABle B18. PT outcomes. III, one placement

\begin{tabular}{lcccc}
\hline \hline \multirow{4}{*}{ Constant } & \multicolumn{4}{l}{ Mental health } \\
\cline { 2 - 5 } & $(1)$ OLS & $(2)$ OLS & $(3)$ OLS & $(4)$ OLS \\
Private & $.176^{* *}$ & .088 & .313 & 0.593 \\
& $(.087)$ & $(.137)$ & $(.571)$ & $(0.399)$ \\
Nonprofit & .042 & .079 & -.106 & -0.170 \\
& $(.101)$ & $(.116)$ & $(.177)$ & $(0.225)$ \\
County & .012 & -.028 & -.092 & -0.101 \\
& $(.080)$ & $(.111)$ & $(.109)$ & $(0.194)$ \\
Private*Violence & .088 & .039 & -.082 & -0.279 \\
& $(.098)$ & $(.101)$ & $(.156)$ & $(0.196)$ \\
Private*Pr. break & & -.144 & -.069 & 0.054 \\
& & $(.201)$ & $(.195)$ & $(0.265)$ \\
Teenager ch. & & -.104 & -.068 & -0.017 \\
Facility ch. & No & $(.154)$ & $(.167)$ & $(0.333)$ \\
Municipality ch. & No & No & Yes & Yes \\
Municipality FE & No & No & Yes & Yes \\
\hline$N$ & 224 & 195 & No & Yes \\
$R$ & .01 & .13 & .21 & .66 \\
\hline \hline
\end{tabular}

Robust standard errors clustered on the facility level in parentheses. One asterisk denotes 10 percent significance level, two asterisks 5 percent significance level and three asterisks 1 percent significance level in a two-sided test. 


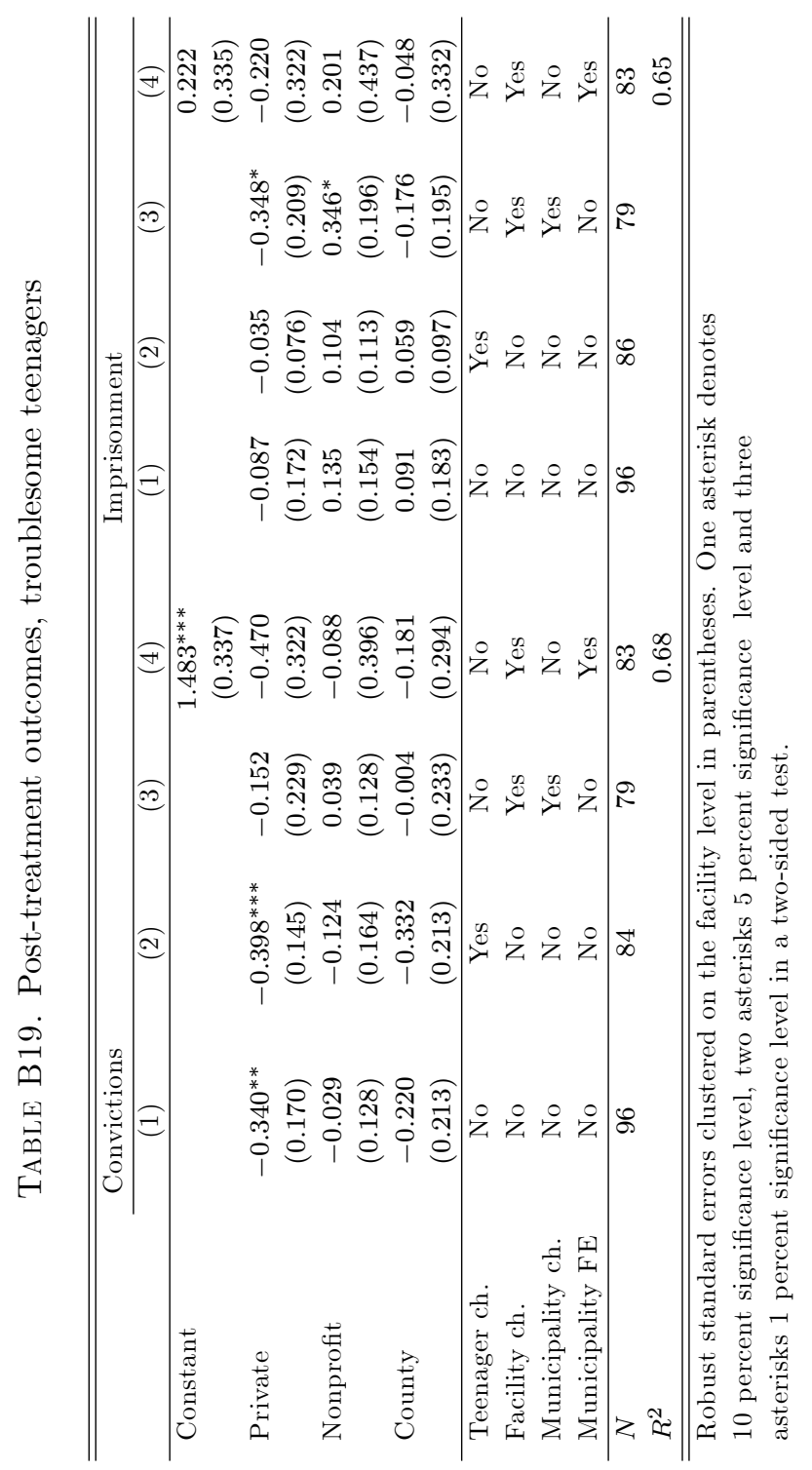


Table B20. Facility Initiative to Breakdown

\begin{tabular}{lcc}
\hline \hline Variable & $(1)$ OLS & $(2)$ OLS \\
\hline Private & $.122^{* *}$ & .104 \\
& $(.057)$ & $(.084)$ \\
Nonprofit & .041 & .106 \\
& $(.043)$ & $(.090)$ \\
County facility & .043 & .074 \\
& $(.045)$ & $(.082)$ \\
Troublesome & $.275^{* * *}$ & $.244^{* * *}$ \\
& $(.065)$ & $(.081)$ \\
Private*Troublesome & $-.237^{* *}$ & $-.220^{* *}$ \\
& $(.092)$ & $(.105)$ \\
\hline Full set of control variables $(\mathbf{X}, \mathbf{Y , Z})$ & No & Yes \\
\hline$N$ & 329 & 284 \\
Number of clusters & 154 & 134 \\
$R^{2}$ & .08 & .20 \\
\hline \hline
\end{tabular}

The standard errors within parentheses have been corrected for clustering at the facility level and heteroskedasticity. Two asterisks denotes 5 percent significance level and three asterisks 1 percent significance level in a two-sided test. 